\title{
Evaluation of the antioxidant potential of N R-ANX-C (a polyherbal formulation) and its individual constituents in reversing haloperidol-induced catalepsy in mice
}

\author{
Albina Arjuman, Vinod Nair*, H.N. Gopalakrishna*, M. N andini
}

Departments of Biochemistry and *Pharmacology, Kasturba Medical College, Mangalore, Karnataka,

India

Received: 22.10 .2006

Revised: 27.12 .2006

Accepted: 10.5.2007

Correspondence to: Nandini M. E-mail: nandinim1232002@yahoo.co.in

\section{Introduction}

Haloperidol is an antipsychotic drug, which is used in the treatment of schizophrenia and other affective disorders. It blocks the dopaminergic action in the nigro-strial pathway leading to high frequency of extrapyramidal motor side effects. ${ }^{[1]}$ In animal models, haloperidol induces a behavioural state known as catalepsy in which the animals are unable to correct externally imposed postures. ${ }^{[2]}$ The use of haloperidol has been associated with an increased level of oxidative stress in the brain..$^{[3]}$ This evidence suggests a possible role for antioxidants in the treatment of haloperidol-induced catalepsy.

The brain is made up of $70 \%$ lipid and any kind of stress is usually manifested by lipid peroxidative damage. ${ }^{[4]}$ The extent of this damage can be used to evaluate the degree of cellular harm. In practical terms, this stress-induced lipid peroxidative damage in the brain can be quantified by either determining the amounts of peroxidative products or the rates of enzymecatalysed reactions neutralizing free radical intermediates such as those of superoxide dismutase (SOD). SOD is a primary, natural, free radical-scavenging, antioxidant enzyme in the body. The estimation of the activity of such antioxidant enzymes such as superoxide dismutase, catalase, glutathione peroxidase etc, can be used to assess the therapeutic effects of different antioxidant agents.

The administration of any exogenous agent is associated with the development of cellular oxidative stress as a result of its metabolism in the body. The ability of the compound to counteract the oxidative stress induced by its metabolism is known as its antioxidant potential. Recently, the evaluation of the extent of cellular oxidative stress has been applied to determine the therapeutic / toxic doses of synthetic and herbal drugs. A step ahead of this approach would be to evaluate 
the best therapeutic dose of a natural or synthetic compound in a specific disease state, giving better or at least similar therapeutic action on a tissue but with the least amount of damage to the same, thus ensuring mammalian well being and avoiding supplementary tissue toxicity.

NR-ANX-C is a polyherbal formulation containing the aqueous extract of $\mathrm{W}$. somnifera (17\% withanolides, $2.1 \%$ w/w), $70 \%$ ethanolic extract of 0 . sanctum ( $17 \%$ Ursolic acid, $2.9 \% \mathrm{w} / \mathrm{w}$ ) and $70 \%$ ethanolic extract of $\mathrm{C}$. sinensis (34\%, total polyphenols $60.1 \% \mathrm{w} / \mathrm{w}$ ). These agents have been used in the Ayurvedic system of medicine for over 3000 years. W. somnifera (Ashwagandha) has been used as a liver tonic, anti-inflammatory agent and antioxidant, in the treatment of bronchial asthma, insomnia, as a nervine tonic in the treatment of senile dementia, cognitive and neurological disorders and Parkinson's disease..$^{[5-8]}$ 0. sanctum (Tulsi, India's Holy Basil) has been shown to have hypoglycemic, hypolipidemic, adaptogenic, antidepressant, hepatoprotective, anticancer, antioxidant, analgesic and antiinflammatory properties. ${ }^{[9-11]} \mathrm{C}$. sinensis (Green tea) has been used in the treatment of cancer, rheumatoid arthritis, high cholesterol levels, cardiovascular disease, infection and other impaired immune functions. It has also been shown to have antioxidant properties. ${ }^{[12]}$

The objective of our study was to evaluate the efficacy of NR-ANX-C and its individual components by virtue of their antioxidant potential in mouse brain using haloperidol-induced catalepsy as our model of investigation.

\section{Materials and Methods}

Prior approval was obtained from the Institutional Animal Ethics Committee, Kasturba Medical College, Mangalore, for conducting this study.

Study design

Adult male Swiss albino mice (25-30 g) were allocated to thirteen groups ( $n=6 /$ group) and housed in polypropylene cages at $27^{\circ} \mathrm{C}$ with $12 \mathrm{~h}: 12 \mathrm{~h}$ light-dark cycle. The animals were allowed free access to food (standard pellet feed) and water. They were allowed an acclimation period of seven days before the study.

A pilot study was carried out and suitable doses were selected. The individual doses used were suspended in $1 \%$ gum acacia and administered orally to the different groups. One group received the vehicle (1\% gum acacia solution) and served as the control. Three groups received NR-ANX-C (10, 25 and $50 \mathrm{mg} / \mathrm{kg}$ ), three groups received W. somnifera (1.7, 4.25 and $8.5 \mathrm{mg} / \mathrm{kg}$ ), three groups received 0 . sanctum (1.7, 4.25 and $8.5 \mathrm{mg} / \mathrm{kg}$ ) and three groups received C. sinensis (3.4, 8.5 and $17 \mathrm{mg} / \mathrm{kg}$ ). Thirty minutes after the administration of these drugs, catalepsy was induced by the i.p. administration of haloperidol at a dose of $1 \mathrm{mg} / \mathrm{kg}$ body weight, in the form of an injectable solution constituted in normal saline. This procedure was repeated for seven days. On the seventh day, catalepsy was measured 240 minutes after haloperidol administration in a manner similar to the method described by Ahtee and Buncombe. ${ }^{[13]}$ All observations were made between 14:00 and 16.00 hours. The animals were placed on a flat surface and their front paws were elevated and placed on a $4 \mathrm{~cm}$-high wooden bar. If the animal maintained the imposed posture for at least
20 seconds, it was said to be cataleptic and given one point. For every additional 20 seconds that the animal continued to maintain the cataleptic posture, one extra point was given. The animals were then sacrificed by cervical dislocation and the SOD activity in brain tissue was estimated.

Assay of SOD

The assay of SOD was carried out based on the SODmediated inhibition of the reduction of nitroblue tetrazolium to blue formazan by superoxide anions as described by Beauchamp and Fridovich. ${ }^{[14]}$

The total protein present in the homogenate was estimated following the method described by Lowry et al. ${ }^{[15]}$ Units of SOD activity determined were expressed in terms of milligrams of total protein (TP).

Preparation of homogenate

The brains isolated from the individual groups of mice were homogenized ( $20 \% \mathrm{w} / \mathrm{v}$ ) in $10 \mathrm{mM}$ Phosphate buffer, $\mathrm{pH} 7.8$. The homogenate was subjected to centrifugation. $0.1 \mathrm{ml}$ aliquot of the homogenate (1:10 dilution) was used for the assay.

Statistical analysis

Statistical analysis was done using ANOVA followed by Dunnett's multiple comparison.

\section{Results}

The cataleptic scores of the present study are given in Table 1. Significant reversal in haloperidol-induced catalepsy $(P<$ 0.01 ) was observed with NR-ANX-C at a dose of $25 \mathrm{mg} / \mathrm{kg}$. This dose was the most effective of the three tested doses. Of the individual constituents of NR-ANX-C, W. somnifera and 0. sanctum at a dose of $8.5 \mathrm{mg} / \mathrm{kg}$ showed a significant reversal in the catalepsy $(P<0.01)$. The result observed with $C$. sinensis though significant when compared to the control, is not as pronounced as with NR-ANX-C, W. somnifera or 0 . sanctum.

The SOD activity in the brain of the mice treated with haloperidol and the test drugs are also presented in Table 1. The SOD activity in the brain was found to be elevated in the haloperidol-treated group. The observed increase was about $66 \%$ above the normal. The test drug formulation, NR-ANX-C showed an overall reduction in SOD activity at all the three doses with a maximum reduction observed in the group treated with $25 \mathrm{mg} / \mathrm{kg}$. In the W. somnifera-treated groups, there was a dose-dependent decrease in the brain SOD activity. Significant $(P<0.05)$ reduction was observed at a dose of $8.5 \mathrm{mg} / \mathrm{kg}$ with W. somnifera. In the 0 . sanctum-treated groups, there was a decrease in the SOD activity at the lower dose with maximum reduction seen at a dose of $4.25 \mathrm{mg} / \mathrm{kg}$. However, with the higher dose $(8.5 \mathrm{mg} / \mathrm{kg})$, there was a slight increase in the SOD activity. Unlike the groups treated with the other constituents of NR-ANX-C, all the C. sinensis-treated groups showed an increase in the SOD activity compared to the control.

\section{Discussion}

Induction of free radicals in mammals by haloperidol is well established. Previous studies have shown that dopamine receptors in the striatum are involved in neuroleptic-induced catalepsy. It has been demonstrated that cataleptic effects of haloperidol are apparently mediated by dopamine receptors localized postsynaptically on strial neurons. ${ }^{[2]}$ It is also well 


\section{Table 1}

Effect of test drugs on haloperidol-induced catalepsy and brain superoxide dismutase activity

\begin{tabular}{|c|c|c|c|c|c|}
\hline Drug groups & Dose & $\begin{array}{c}\text { Catalepsy scores } \\
(n=6)\end{array}$ & $\begin{array}{c}S O D(U / m g T P) \\
(n=3)\end{array}$ & $\begin{array}{l}\% \text { decrease } \\
\text { from control }\end{array}$ & $\begin{array}{c}\% \text { increase from } \\
\text { control }\end{array}$ \\
\hline Normal (no haloperidol) & & & $5.28 \pm 0.28$ & & \\
\hline control & $10 \mathrm{ml} / \mathrm{kg}$ & $37.33 \pm 1.20$ & $8.81 \pm 0.28$ & & \\
\hline \multicolumn{6}{|l|}{ (1\% gum acacia) } \\
\hline \multirow[t]{3}{*}{ NR-ANX-Cw } & $10 \mathrm{mg} / \mathrm{kg}$ & $12.33 \pm 0.83^{* *}$ & $7.75 \pm 0.31$ & 12.03 & \\
\hline & $25 \mathrm{mg} / \mathrm{kg}$ & $10.5 \pm 0.99^{\star *}$ & $6.56 \pm 0.79$ & 25.53 & \\
\hline & $50 \mathrm{mg} / \mathrm{kg}$ & $13.5 \pm 1.08^{* *}$ & $6.95 \pm 0.91$ & 21.11 & \\
\hline \multirow[t]{3}{*}{ W. somnifera } & $1.7 \mathrm{mg} / \mathrm{kg}$ & $21.5 \pm 1.58^{\star *}$ & $9.88 \pm 0.72$ & & 12.14 \\
\hline & $4.25 \mathrm{mg} / \mathrm{kg}$ & $16.16 \pm 0.47^{* *}$ & $6.99 \pm 0.28$ & 20.66 & \\
\hline & $8.5 \mathrm{mg} / \mathrm{kg}$ & $11.5 \pm 0.56^{\star *}$ & $6.18 \pm 0.49^{*}$ & 29.85 & \\
\hline \multirow[t]{3}{*}{ O. sanctum } & $1.7 \mathrm{mg} / \mathrm{kg}$ & $14.66 \pm 0.42^{* *}$ & $8.58 \pm 0.62$ & & 2.61 \\
\hline & $4.25 \mathrm{mg} / \mathrm{kg}$ & $13.6 \pm 0.42^{* *}$ & $6.65 \pm 0.86$ & 24.5 & \\
\hline & $8.5 \mathrm{mg} / \mathrm{kg}$ & $11.33 \pm 0.49^{* *}$ & $9.57 \pm 0.58$ & & 8.63 \\
\hline \multirow[t]{3}{*}{ C. sinensis } & $3.4 \mathrm{mg} / \mathrm{kg}$ & $22.89 \pm 0.74^{* *}$ & $8.86 \pm 0.09$ & & 0.56 \\
\hline & $8.5 \mathrm{mg} / \mathrm{kg}$ & $19.66 \pm 1.2^{\star *}$ & $9.92 \pm 0.34$ & & 12.6 \\
\hline & 17 mg/kg & $20.5 \pm 0.56^{\star *}$ & $10.85 \pm 0.37$ & & 23.15 \\
\hline
\end{tabular}

All values are Mean \pm SE; Statistical analysis by One-way ANOVA followed by Dunnett's Multiple Comparison Test; $P<0.05$ ** $P<0.01$

established that administration of haloperidol leads to an increase in the oxidative stress in the brain tissue. ${ }^{[3]}$ The increase in SOD observed in the present study supports the above concept.

Superoxide formation is a major factor in oxygen toxicity and the superoxide dismutase enzyme constitutes an essential defence against it. Under normal conditions, decreased activity of antioxidant enzymes, viz. SOD, glutathione peroxidase (GSHPX) and catalase in the brain leads to accumulation of oxidative free radicals resulting in degenerative effects ${ }^{[6]} \mathrm{An}$ increase in these enzymes under normal conditions would represent increased antioxidant activity and a protective mechanism in neuronal tissue, thus, constituting the first line of defence against oxidative stress in our body. However, in the presence of a free radical-quenching agent, the induction of the antioxidant enzymes is minimized. So, an overall decrease in cataleptic scores and also SOD activity in the NR-ANX-C-treated groups indicates the ability of NR-ANX-C to combat oxidative stress in brain tissue and reduce the severity of haloperidol-induced catalepsy.

With regard to the individual constituents, W. somnifera ${ }^{[6-8]}$ and 0 . sanctum ${ }^{[10]}$ showed a dose-dependent decrease in the cataleptic scores. Of the two, W. somnifera showed a dosedependent decrease in SOD activity while 0 . sanctum showed decrease in SOD activity only at the two lower doses (1.7 and $4.25 \mathrm{mg} / \mathrm{kg}$ ).

The increase in SOD activity in C. sinensis-treated groups is contrary to the effects of the test drug or its individual components namely, W. somnifera and 0 . sanctum on SOD activity. The reduced SOD activity seen in the test drug NR-ANX$C$ treated groups could be possibly due to the phytochemicals present in it which have been shown to possess antioxidant activity.

From these observations, it can be inferred that the test drug NR-ANX-C shows significant antioxidant activity, which can be attributed to its role in reversing haloperidol-induced catalepsy.

Of its individual constituents, W. somnifera appears to be the major contributor of antioxidant activity leading to the reduction of SOD activity. The antioxidant activity of W. somnifera could be attributed to the direct scavenging of free radicals by polyphenols present in it.

The antioxidant activity of NR-ANX-C could be possibly due to the direct scavenging of the superoxide radicals by the polyphenols $s^{[0,12,16]}$ or the flavanoids known to be present in its individual constituents which have been established to have an antioxidant potential. From the present study, it can be concluded that the polyherbal formulation, NR-ANX-C and its individual components can be beneficial adjuvants in the treatment of drug-induced extrapyramidal side effects and related disorders. Clinical trials in humans suffering from Parkinson's disease may provide us with greater evidence for the neuroprotective activity of this formulation.

\section{Acknowledgment}

We are grateful to Natural Remedies Pvt. Ltd. Bangalore for providing us with the test drugs. We also appreciate the technical assistance offered to us by P. Dorababu, Lovelyn Joseph, Rose Merin Chacko, Rejeesh E. P. and Anjali Varghese (Postgraduates, Dept. of Pharmacology, Kasturba Medical College, Mangalore, Karnataka).

\section{References}

1. Farde L, Nordström AL, Wiesel FA, Pauli S, Halldin C, Sedvall G. Positron emission tomographic analysis of central D1 and D2 dopamine receptor occupancy in patients treated with classical neuroleptics and clozapine: Relation to extrapyramidal side effects. Arch Gen Psychiatry 1992;49:538-44.

2. Sanberg PR. Haloperidol-induced catalepsy is mediated by postsynaptic dopamine receptors. Nature 1980;284:472-3.

3. Sagara $Y$. Induction of reactive oxygen species in neurons by haloperidol. $\mathrm{J}$ Neurochem 1998;71:1002-12.

4. Kedar NP. Can we prevent Parkinson's and Alzheimer's disease? J Postgrad Med 2003;49:236-45.

5. Monograph. Withania somnifera. Altern Med Rev 2004;9:211-4.

6. Naidu PS, Singh A, Kulkarni SK. Effect of Withania somnifera root extract on 
haloperidol induced orofacial dyskinesia: Possible mechanisms of action. J Med Food 2003;6:107-14.

7. Mishra LC, Singh BB. Scientific Basis for the therapeutic use of Withania somnifera (Ashwagandha): A review. Altern Med Rev 2000;5:334-46.

8. Bhattacharya A, Ghosal S, Bhattacharya SK. Antioxidant effect of Withania somnifera glycowithanolides in chronic footshock stress-induced perturbations of oxidative free radical scavenging enzymes and lipid peroxidation in rat frontal cortex and striatum. J Ethnopharmacol 2001;74:1-6.

9. Gupta SK, Prakash J, Srivastava S. Validation of traditional claim of tulsi, Ocimum sanctum Linn as a medicinal plant. Indian J Exp Biol 2002;40:765-73.

10. Uma Devi P. Radioprotective, anticarcinogenic and antioxidant properties of the Indian holy basil, Ocimum sanctum (Tulsi). Indian J Exp Biol 2001;39:185-90.

11. Bhargava KP, Singh N. Anti-stress activity of Ocimum sanctum Linn. Indian J Med Res 1981;73:443-51.

12. Tewari S, Gupta V, Bhattacharya S. Comparative study of antioxidant potential of tea with and without additives. Indian J Physiol Pharmacol 2000;44:215-9.

13. Ahtee $L$, Buncombe $G$. Metoclopramide induces catalepsy and increases striatal homovanillic acid content in mice. Acta Pharmacol Toxicol (Copenh)
1974;35:429-32.

14. Beauchamp C, Fridovich I. Superoxide dismutase: Improved assays and an assay applicable to acrylamide gels. Anal Biochem 1971;44:276-87.

15. Peterson GL. Review of the folin phenol protein quantification method of Lowry, Rosenbrough, Farr and Randall. Anal Biochem 1979;100:201-20.

16. Parihar MS, Hemnani T. Phenolic antioxidants attenuate hippocampal neuronal cell damage against kainic acid induced excitotoxicity. J Biosci 2003;28:121-8.

Presentation at a meeting: part of the work was presented Organization: $38^{\text {th }}$ Annual Conference of the Indian Pharmacological Society

Place: Chennai

Date: December 2005.

\section{Author Help: Choosing an appropriate category of article for faster publication}

The manuscript system (www.journalonweb.com) allows the authors to check a likely publication date for a new ly submitted article. Based on number of articles in review, number of accepted articles and acceptance rate, the system estimates the likely publication date for an article submitted on a given date.

If there are too many articles in a category e.g., case report, a newly submitted case report if accepted may have to wait for a long period before publication. Hence, the author can check other categories e.g. letter to editor or images, for such paper and submit to another category of articles. 